\title{
Investigations in spontaneous discounting
}

\author{
DANiEL M. OPPENHEIMER \\ Princeton University, Princeton, New Jersey \\ AND \\ Benoît Monin \\ Stanford University, Palo Alto, California
}

\begin{abstract}
Oppenheimer's (2004) demonstration that causal discounting (when the presence of one cause casts doubt on the presence of another) can happen spontaneously addressed the standing concern that discounting was an artifact of experimental demands, but these results could have resulted from memory inhibition. The present studies rule out this alternative using the same surname frequency estimation paradigm. In Study 1, individuals discounted surname familiarity even when it could be attributed to semantic meaning; in Study 2, participants under cognitive load discounted less; in Study 3, participants who were promised a prize for accuracy discounted more. All three results conform to a spontaneous causal discounting account better than to the inhibition alternative.
\end{abstract}

When people reason about causation, they tend to prefer to think of a single event as having a single cause. This leads to what has been called causal discounting. When one cause is known to be present, people discount alternate causes as also being present, even though these multiple causes are not necessarily mutually exclusive (Einhorn \& Hogarth, 1986). The attribution and causal reasoning literature is full of studies demonstrating this phenomenon (e.g., Hansen \& Hall, 1985; Kun, Murray, \& Sredl, 1980; Morris \& Larrick, 1995; Nisbett \& Ross, 1980; Read, 1987; Read \& Marcus-Newhall, 1993).

However, critics have argued that the seeming prevalence of discounting is due to the manner in which it has been studied (McClure, 1998). The fact that discounting can be found under laboratory conditions specifically designed to elicit it does not necessarily mean that it occurs frequently in more naturalistic causal reasoning situations. For example, McClure argued that methodological artifacts have led to a false belief among psychologists that discounting is a fairly common phenomenon. In particular, the common methodology of a single bipolar scale-for example, with person on one end and situation on the other (e.g., Elig \& Frieze, 1979; F. D. Miller, Smith, \& Uleman, 1981; Thibaut \& Riecken, 1955) - artificially inflates the frequency by which people discount. When this confound is accounted for and individuals are less constrained in the causal attributions that they are allowed to make, many discounting effects disappear (e.g., Lalljee, Watson, \& White, 1982; Wimer \& Kelley, 1982). Similarly, pragmatic implicature (Grice, 1975) can subtly create demand characteristics (cf. Hilton, 1995). When experimenters explicitly point out the presence of a cause, participants might construe that as a hint that they should discount, even if they would not have done so naturally. Because of this, some psychologists believe that discounting is actually a fairly infrequent phenomenon in ecologically valid settings (McClure, 1998; Rosenfield \& Stephan, 1977).

To get around these critiques, researchers have begun to adopt subtler approaches to the study of discounting. One such approach is to investigate spontaneous discounting — when people spontaneously generate alternative causes and engage in discounting in the absence of an experimenter-specified alternate cause (Oppenheimer, 2004, 2006; Oppenheimer \& Frank, 2007). For example, Oppenheimer (2004) asked participants to judge surname frequencies. Typically, participants would use the ease of bringing exemplars to mind as a proxy for frequency, a tendency known as the availability heuristic (Tversky \& Kahneman, 1973). However, Oppenheimer (2004) found that, when surnames were famous (e.g., Bush, Clinton, etc.), people underestimated name frequencies. Oppenheimer argued that participants spontaneously recognized that the cause of availability was fame and thus discounted frequency as a cause of availability. As the participants were never explicitly told the alternative cause, this would suggest that discounting does indeed occur, even in the absence of experimental demand.

\section{Discounting or Inhibition?}

However, there is another possible explanation for these findings. It may be that the famous names impaired retrieval of alternative exemplars and thus reduced the experience of availability. A large body of literature on memory shows that bringing certain exemplars to mind can inhibit subsequent retrieval of other exemplars (e.g., Anderson \& Bjork, 1994; Johnson, Häubl, \& Keinan, 2007). This leads

D. M. Oppenheimer, doppenhe@princeton.edu 
to the counterintuitive findings from the part-set cuing paradigm, where providing participants with a subset of the items that they are asked to retrieve (e.g., "seeding" them with 10 of the 50 U.S. states before asking them to recall all of the states) actually impairs overall retrieval performance (Nickerson, 1984).

It seems plausible that upon exposure to a famous surname (e.g., Bush) the famous exemplar (e.g., President George Bush) comes to mind so strongly that it inhibits one's ability to retrieve other exemplars. This difficulty in retrieving other exemplars would lead the name to feel less available and could yield underestimation of frequency without need for spontaneous discounting. In other words, it is unclear whether Oppenheimer's (2004) results are due to discounting or to memory inhibition.

The studies presented here were designed to rule out this inhibition interpretation of the name-frequency discounting effect. One way to discriminate between these possibilities is a domain in which the spontaneously generated alternative cause would not lead participants to bring to mind specific exemplars. One such alternative cause for a feeling of availability or fluency ${ }^{1}$ would be semantic meaning. Some surnames, such as Light and Rose, have meanings aside from personal identifiers. If participants attribute their metacognitive experience of familiarity to recognition of the semantic meaning of the word, discounting theory would predict underestimation of surname frequency. However, with no exemplar of a person with that name blocking retrieval of other exemplars, in the absence of discounting, one would expect accurate estimates or overestimations of such surnames.

\section{STUDY 1}

Borrowing the paradigm from Oppenheimer (2004), participants were asked to determine which of a pair of surnames was more frequent in the U.S. population.

\section{Method}

Participants. Ninety-five Stanford University undergraduates participated as partial completion of a course requirement. The surveys were handed out in a packet of approximately 40 unrelated questionnaires, and participants were given a week to complete the entire packet.

Design and Stimuli. Participants made forced-choice judgments of surname frequency in the American population. Seventeen pairs of surnames were created, such that a surname with semantic meaning was compared with a surname with no obvious semantic meaning. For each meaningful surname, a slightly less frequent meaningless surname was also selected. In this way, if participants believed the meaningful surname to be less common (as discounting theory predicts), they would be incorrect, thus eliminating the possibility that they actually knew the answer.

The surnames vary greatly in their actual frequency in the population, ranging from the 157 th most common surname (Rose) to the 63,315 th most common surname (Hippo). Surname frequencies were taken from the United States Census Bureau (2002) homepage. For a list of the names used in this experiment, see Table 1.

Participants were asked to select which surname in each pair was more common in the U.S. population. The pairs were embedded among a set of 11 meaningless-meaningless decoy pairs to prevent participants from identifying the treatment of interest and thus to reduce the possibility of demand characteristics.
Table 1

\begin{tabular}{lclcc}
\multicolumn{5}{c}{$\begin{array}{c}\text { Name Pairs and the Number of Participants } \\
\text { Who Chose Each Name From Study 1 }\end{array}$} \\
\hline $\begin{array}{l}\text { Meaningful } \\
\text { Name }\end{array}$ & $\begin{array}{c}\text { Number } \\
\text { Chosen }\end{array}$ & $\begin{array}{c}\text { Meaningless } \\
\text { Name }\end{array}$ & $\begin{array}{c}\text { Number } \\
\text { Chosen }\end{array}$ & $\chi^{2}$ \\
\hline Battle & 28 & Hinton & 66 & $15.36^{*}$ \\
Cotton & 20 & Fulton & 74 & $31.02^{*}$ \\
Flowers & 21 & Maxwell & 73 & $28.76^{*}$ \\
Fountain & 11 & Kaplan & 83 & $55.15^{*}$ \\
Hippo & 7 & Gundry & 87 & $68.08^{*}$ \\
House & 13 & Chen & 82 & $50.11^{*}$ \\
Light & 28 & Whitt & 66 & $16.67^{*}$ \\
Money & 6 & Gooding & 88 & $7.53^{*}$ \\
Moon & 16 & Chan & 78 & $40.89^{*}$ \\
Numbers & 3 & Kessler & 92 & $83.38^{*}$ \\
Pagan & 5 & Goldberg & 90 & $76.05^{*}$ \\
Rose & 18 & Hawkins & 76 & $35.78^{*}$ \\
Snow & 47 & Cline & 47 & 0 \\
Stone & 39 & Dunn & 55 & 2.72 \\
Strong & 29 & Roth & 66 & $14.41^{*}$ \\
Towns & 16 & Wayne & 77 & $40.01^{*}$ \\
Water & 62 & Vero & 32 & $9.57^{*}$ \\
\hline
\end{tabular}

Note-Each meaningful name is actually more frequent in the U.S. population than its meaningless counterpart. Water versus Vero is statistically significant in the opposite direction from the main trend. $* p \leq .05$.

\section{Results}

Some participants left items blank. Therefore, the number of participants per trial varied, ranging from 93 in the case of Towns, to 95 in the cases of House, Numbers, Pagan, and Strong. For 15 of the 17 pairs, participants selected the meaningless surname as more common. Within pairs, this trend was statistically significant for 14 of the 15 pairs $\left[\chi^{2}(1)>14, p<.01\right]$. For one pair (Water vs. Vero), participants reliably selected the meaningful surname $\left[\chi^{2}(1)=9.57, p<.01\right]$, and for one pair (Snow vs. Cline), participants were equally divided in their choices. Across all pairs, the trend to select the meaningless name was statistically significant $\left[\chi^{2}(1, n=94.17)=27.36\right.$, $p<.01] .^{2}$ For a summary of the results, see Table 1.

\section{Discussion}

As predicted by discounting theory, participants erroneously believed that the names with semantic meaning were less common than their counterparts without meaning. ${ }^{3}$ This is a first step toward ruling out interference as an alternative interpretation for the Oppenheimer (2004) results. However, although this study suggests that the effects are not due to particular exemplars' inhibiting retrieval of other exemplars, a critic could note that other forms of interference have been observed in the literature. Most notably, inhibition effects have been shown using the cue-independent probe paradigm in the retrieval-induced forgetting literature (Levy \& Anderson, 2002).

In retrieval-induced forgetting, participants memorize several exemplars of a category (e.g., colors - purple, red) and are prompted to retrieve a subset of those exemplars (e.g., color: pu___ ). Unsurprisingly, when subsequently asked to recall the colors, participants are better able to recall exemplars that they had practiced retrieving. However, participants also show impaired recall for nonretrieved exemplars compared to baseline. That is, retrieving purple impairs the recall of red. Importantly, retrieval can also 
inhibit recall for items in other categories with related semantic meanings. That is, after having retrieved the color purple, participants might show reduced recall of the fruit orange or the flower rose (see Levy \& Anderson, 2002, for a review). One could argue, then, that retrieving a concept such as ROSE might inhibit retrieval of not only other flowers but also other members of other categories associated with rose, such as people with the last name Rose. ${ }^{4}$

To get around this critique, we adopted a different approach in Study 2. Researchers in judgment and decisionmaking have posited two systems of reasoning. System 1 is fast, effortless, and heuristic, whereas System 2 is slow, effortful, and analytic (for a review, see Kahneman \& Frederick, 2002). As the name suggests, the availability heuristic has been described as a System 1 reasoning strategy. Causal discounting, however, is typically thought to be an effortful System 2 strategy (e.g., Gilbert, Pelham, $\&$ Krull, 1988). This suggests that the addition of cognitive load should greatly impair people's ability to discount but should have little impact on the effortless availability heuristic. In other words, according to discounting theory, under cognitive load, the effects observed in spontaneous discounting paradigms should disappear or even reverse.

In contrast, an account of these findings on the basis of inhibition should not predict reversals under cognitive load. If the findings were due to increased retrieval difficulty due to inhibition, adding cognitive load should only make retrieval more difficult and should lead, if anything, to an enhancement of the effect. To test these competing hypotheses, in Study 2, we examined the influence of cognitive load on spontaneous discounting in surname frequencies.

\section{STUDY 2}

\section{Method}

Participants. Thirty-two Stanford University undergraduates participated to fulfill part of a course requirement.

Design and Stimuli. The design of this study was adapted from the paradigm of Gilbert et al. (1988). As did those in Study 1, participants made forced-choice judgments of surname frequency in the American population; however, in this study, the alternative cause was fame, rather than semantic meaning, so as to more closely par-

Table 2

Famous and Nonfamous Names From Study 2

\begin{tabular}{ll}
\hline Famous Name & Nonfamous Name \\
\hline Bush & Watts \\
Powell & Jenkins \\
Clinton & Gomes \\
Nixon & Maynard \\
Cheney & Monk \\
DiCaprio & Maultsby \\
Snipes & Blaylock \\
Affleck & Aiken \\
Pitt & Brownlee \\
Monroe & Hodge \\
Hanks & Boudreaux \\
Osbourne & Border \\
Springsteen & Steigerwald \\
Kravitz & LaPerle \\
Tyson & Pate \\
\hline
\end{tabular}

allel Oppenheimer's (2004) original findings. Sixteen pairs of surnames were created, such that a surname from a famous individual was compared with a surname with which no obvious famous individual was associated. Unlike those in Study 1, the decoy names for Study 2 were slightly more frequent than the famous names.

To ensure that observed effects were not category specific, surnames from several different categories were chosen: politicians, musicians, actors, and athletes. The surnames varied greatly in their actual frequency in the population, ranging from the 304th most common surname (Bush) to the 53,180th most common surname (Affleck). Surname frequencies were taken from the United States Census Bureau (2002) homepage. For a list of the critical names and their associated foils, see Table 2.

Additionally, 26 decoy pairs were created to disguise the experimental hypothesis. Each of the filler pairs was composed of two names unassociated with any obvious famous individual. This was to prevent participants from identifying the treatment of interest and thus to reduce the possibility of demand characteristics.

Finally, a set of eight individual names was selected for the load induction procedure (described below).

There were two between-subjects conditions: no load and load. In both conditions, there were two types of trials: pair name and single name. In pair-name trials, a pair of names would appear on the computer screen in front of the participants. When this occurred, participants in both conditions were instructed to determine which name in each pair was more frequent. In single-name trials, one of the eight individual names appeared in the center of the screen. For these trials, participants in the load condition were told to attempt to memorize the name on the screen and that their memory would be tested at the end of the experiment. Participants in the no-load condition were instructed to judge whether the individual name was more or less frequent than their own last name.

The experiment was front-loaded with single-name trials. In this way, participants in the load condition were attempting to remember at least seven items by the time the relevant frequency judgments were made. As such, much of their cognitive capacity was committed to the memory task by the time the judgment task arose. Participants in the no-load condition were not attempting to remember any names and had full use of their cognitive resources during the frequency estimations.

Following the judgment trials, a manipulation check was run. On a separate page, participants were given all of the surnames used and were instructed, "For each surname listed on this page, please list all the individuals that you can think of who have this surname." This manipulation check ensured that participants knew of the famous individuals in the study and that the nonfamous surnames were not local celebrities.

\section{Results and Discussion}

The name "Elway" was discarded, because fewer than half of the participants were able to successfully pass the manipulation check; no other names were missed by more than 1 participant. For each of the remaining 15 names, people were more likely to choose the famous name as more frequent when they were under cognitive load $(M=$ $80 \%)$ than when under no load $(M=59 \%)$. This effect was statistically reliable using both a participant-level analysis $[t(28)=3.27, p<.05]$ and item-level analysis $[t(14)=4.93, p<.05]$. The data are displayed in graphical form as Figure 1.

Although these findings do not conform to the predictions of a memory inhibition account, they are in line with discounting theory. As cognitive resources dwindle, cognitively effortful discounting is less prevalent, which leads people to rely more on availability and thus to overestimate the frequency of famous names. Given Morris 

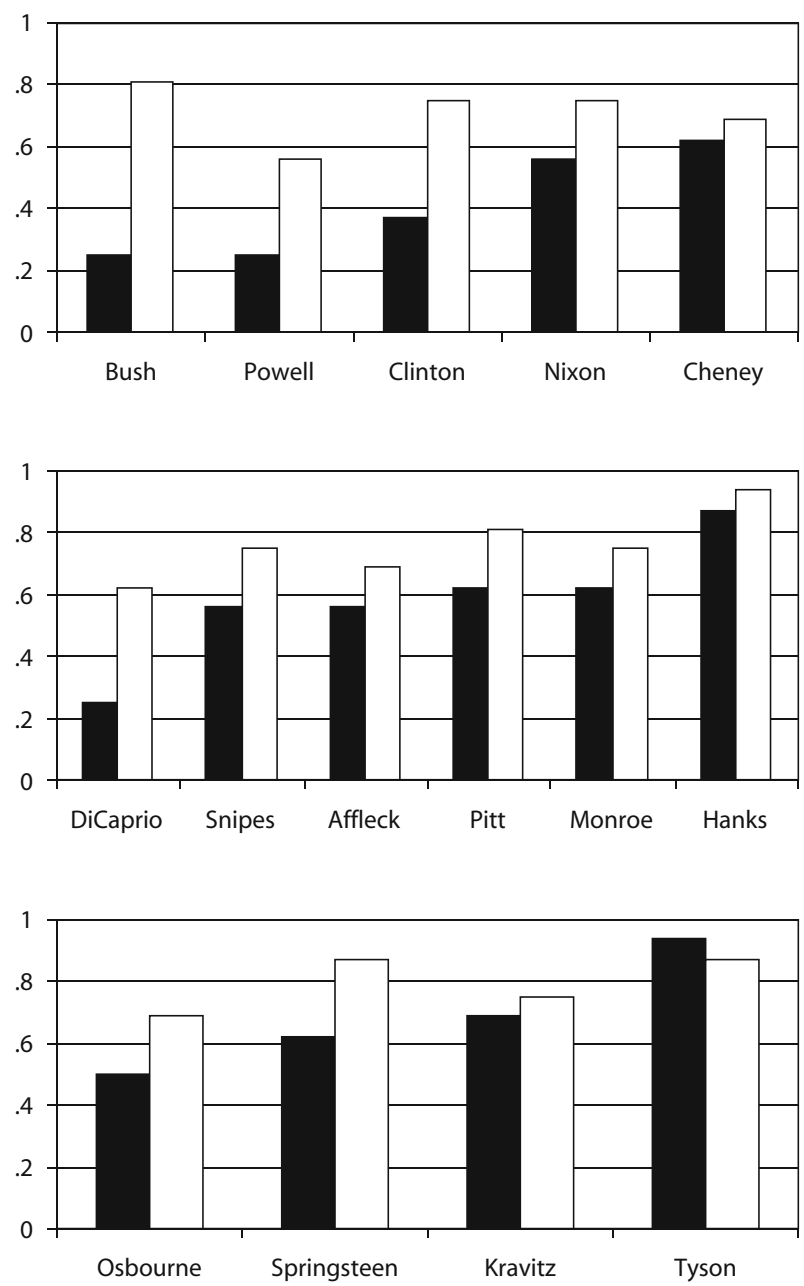

Figure 1. Proportion of participants choosing a famous name to be more frequent in Study 2 while under load (white bars) and no load (black bars). Participants were much more likely to discount fluency when not under load.

and Larrick's (1995) discussion of the normative nature of discounting, it is worth pointing out that putting people under cognitive load did not make them any more accurate. In fact, because the decoy names in Study 2 were more common than the famous names, people who were able to discount showed improved accuracy. Under cognitive load, people tended to overestimate the frequency of every famous name in the sample - a classic availability bias. In other words, although discounting can lead to errors in its own right (Oppenheimer, 2004), it is fundamentally a correction process (Kahneman \& Frederick, 2002) and can, under certain conditions, lead to more accurate judgment.

In Study 3, we sought converging evidence for the discounting account over the inhibition account. Although, in Study 2, we prevented people from engaging in System 2 processes, such as discounting by applying cognitive load, in Study 3, we attempted to augment the use of System 2 reasoning by increasing motivation. Previous research has shown that motivated participants typically engage in more deliberative, corrective processes (Bless \& Schwarz, 1999). As such, discounting theory predicts that discounting should increase as participants are more motivated to get the answers correct.

\section{STUDY 3}

\section{Method}

Participants. Sixty participants recruited from public areas in downtown San Francisco participated in exchange for the possibility of winning a California State Lottery ticket.

Design and Stimuli. Participants made forced-choice judgments of surname frequency in the American population. Eight pairs of surnames were created, such that a surname from a famous individual was compared with a surname with which no obvious famous individual was associated. The famous surnames came from political figures (George Bush, Richard Nixon, Colin Powell), actors (Wesley 
Table 3

Famous and Nonfamous Names From Study 3

\begin{tabular}{ll}
\hline Famous Name & Nonfamous Name \\
\hline Bush & Stevenson \\
Powell & Jenkins \\
Nixon & Maynard \\
Snipes & Blaylock \\
Springsteen & Steigerwald \\
Kravitz & LaPerle \\
Sosa & Carney \\
Wayne & Arthur \\
\hline
\end{tabular}

Snipes, John Wayne), singers (Lenny Kravitz, Bruce Springsteen), and athletes (Sammy Sosa). The surnames varied greatly in their actual frequency in the population, ranging from the 304th most common surname (Bush) to the 14,858 th most common surname (Kravitz). The nonfamous names were Stevenson, Maynard, Jenkins, Blaylock, Arthur, LaPerle, Steigerwald, and Carney. For a list of the critical names and their associated foils, see Table 3. Surname frequencies were taken from the U.S. Census Bureau (2002) homepage.

Additionally, as in Studies 1 and 2, 20 decoy pairs were created to disguise the experimental hypothesis. This was to prevent participants from identifying the treatment of interest and thus to reduce the possibility of demand characteristics.

Participants were instructed to guess which name in each pair was more common in the U.S. population. Half of the participants were told that, regardless of their performance on this task, they would be compensated with a California State Lottery ticket (low motivation). The other half of the participants were told that, in order to receive a lottery ticket, they needed to be correct on at least $75 \%$ of the pairs (high motivation). Yoking reward to performance should motivate participants to take the task seriously, to think harder about the ques- tions in an attempt to be more accurate, and, therefore, to engage in more discounting.

\section{Results and Discussion}

Some participants left items blank. Therefore, the numbers of participants per trial varied, ranging from 28 in the case of Wayne to 31 in the case of Springsteen. On average, participants were more likely to judge the nonfamous name to be more frequent when they believed that their reward was contingent on good performance $(M=54 \%)$ than when they were not motivated by a reward $(M=41 \%)$. A participant-level analysis showed this difference to be statistically reliable $[t(58)=2.25, p<$ $.05]$. This trend held for seven of the eight names, ${ }^{5}$ and a paired-samples $t$ test with name as the unit of analysis also showed a reliable difference $[t(7)=2.54, p<.05]$. The data are displayed in graphical form as Figure 2.

As predicted by discounting theory, providing participants with a motivation to perform well increased the rate of discounting. It is not clear how a memory-inhibition model would account for these findings.

\section{GENERAL DISCUSSION}

Across three studies, we found evidence for spontaneous discounting. Although previous demonstrations of spontaneous discounting of metacognitive states have been confounded by the possibility that the effects were driven by memory inhibition, the present studies were designed to rule out that confound. In Study 1, the spontane-
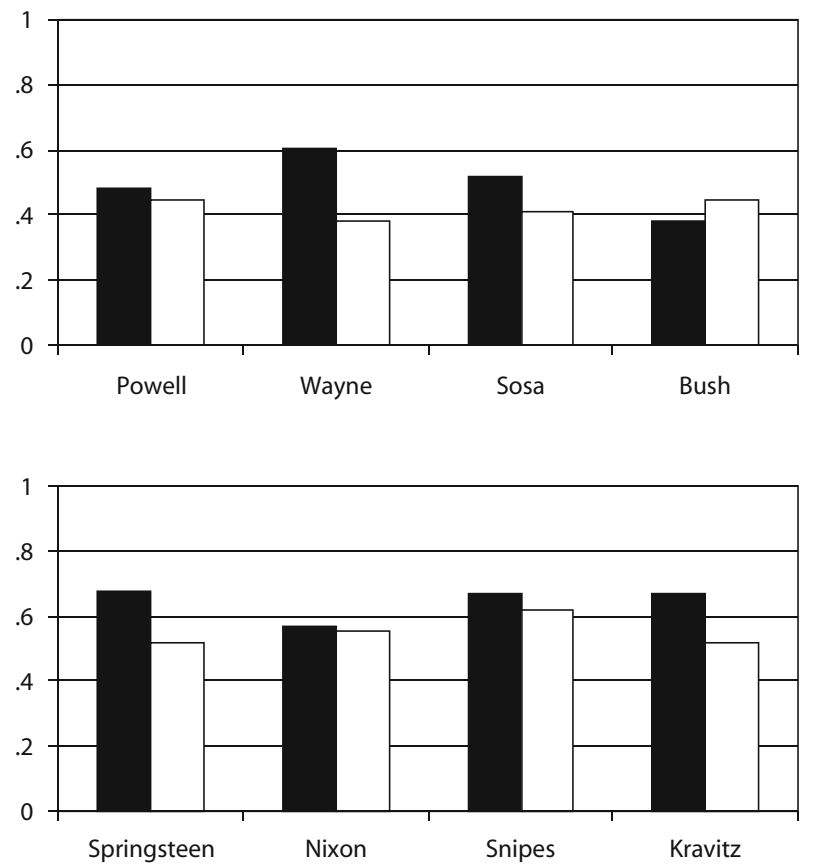

Figure 2. Proportion of participants choosing a famous name to be more frequent in Study 3 while motivated (white bars) and while not motivated (black bars). Participants were more likely to discount fluency when motivated. 
ously generated alternate cause of fluency was semantic meaning, which is less likely to produce an inhibition effect than when the alternate cause is a particular exemplar. In Study 2, we were able to eliminate discounting effects by imposing cognitive load, consistent with the literature on discounting (e.g., Gilbert et al., 1988) but not with an interpretation of our results in terms of inhibition effects. Finally, in Study 3, we were able to facilitate discounting effects by increasing motivation for accuracy. This again conforms to discounting literature but is challenging to explain using an inhibition account.

All of the effects presented in this article are based on binary comparisons of estimates of the frequency of famous and nonfamous names. Thus, it is ambiguous whether lower estimates of frequency for famous names result from discounting of the famous names or from augmenting of the nonfamous names. Two factors help lay this concern to rest. First, although it follows from our theory that load (Study 2) and motivation (Study 3) should, respectively, decrease and increase discounting as observed, no compelling model would predict that they would lead to, respectively, greater and smaller augmentation on the nonfamous names. Second, and maybe more important, these findings can be disambiguated using converging evidence from Oppenheimer's (2004) original studies.

For example, Oppenheimer (2004) asked participants to estimate how many times certain letters would occur in a typical text of 10,000 letters. Some participants were first asked to report their own initials, providing an alternate cause, aside from frequency, for the availability/fluency of those particular letters. These participants reported that the letters in their initials occurred significantly less frequently than did participants who had not been primed. Furthermore, other studies have demonstrated spontaneous discounting using categorization tasks (Oppenheimer, 2004, Study 2) or Likert scales (Oppenheimer, 2006; Oppenheimer \& Frank, 2007) as dependent measures. None of these measures involved comparisons, and, thus, none are subject to the ambiguity of interpretation inherent in binary choice tasks. In light of this convergent evidence, it seems reasonable to similarly interpret the present paradigm as demonstrating discounting of famous names, rather than augmenting of nonfamous names.

This new evidence for spontaneous discounting, free of the concerns about memory inhibition, has important implications for the study of causal reasoning. Previous researchers have questioned the prevalence of discounting in naturalistic settings and suggested that the seeming pervasiveness of the phenomenon in the literature was to a large extent, due to confounded experimental procedures (e.g., McClure, 1998). Although the criticisms of many of the paradigms used to investigate discounting remain valid, and researchers should take care to avoid inducing discounting through experimental and pragmatic artifacts, it appears that discounting is a real phenomenon that can be observed even in the absence of such confounds. Because discounting has important implications for understanding the nature of causal reasoning (cf. Einhorn \& Hogarth, 1986), it will be important for researchers to continue to study the phenomenon, but to do so using more nuanced approaches, such as the ones presented in this article.

Research on fluency-based heuristics has provided a wide array of evidence that individuals spontaneously recognize and discount judgment-irrelevant sources of fluency (Oppenheimer, 2004; Schwarz, 2004). However, the exact mechanisms that are used in this process remain elusive, and it is not yet well understood how people search through memory for potential causes, nor how they go about discounting once multiple potential causes are found. This remains a rich area for future research.

Note that, although we focus on discounting of metacognitive states in this article, spontaneous discounting is not limited to this domain. For example, as causalreasoning-based models of categorization have become more prevalent, researchers have begun investigating how people might discount cues denoting category membership (Oppenheimer, Tenenbaum, \& Krynski, 2009). For example, although a bad smell may typically be a useful cue for categorizing an animal as a skunk, if the animal has been wading through sewage, the bad smell becomes much less diagnostic.

With the growing prevalence of causal Bayes Nets and theory-based Bayesian models to explain diverse phenomena across learning and reasoning (for a review, see Tenenbaum, Griffiths, \& Kemp, 2006), findings in the area of causal reasoning have increasing applicability to cognition more generally. This suggests that discounting could have broader implications across higher-order reasoning and that the spontaneous discounting paradigm has the potential to yield interesting insight into how the mind works.

\section{AUTHOR NOTE}

Correspondence concerning this article should be addressed to D. M. Oppenheimer, Department of Psychology, Princeton University, Green Hall, Princeton, NJ 08540 (e-mail: doppenhe@princeton.edu).

\section{REFERENCES}

Alter, A. L., \& Oppenheimer, D. M. (2009). Uniting the tribes of fluency to form a metacognitive nation. Manuscript submitted for publication.

Anderson, M. C., \& BJork, R. A. (1994). Mechanisms of inhibition in long-term memory: A new taxonomy. In D. Dagenbach \& T. H. Carr (Eds.), Inhibitory processes in attention, memory, and language (pp. 265-325). San Diego: Academic Press.

Bless, H., \& Schwarz, N. (1999). Sufficient and necessary conditions in dual process models: The case of mood and information processing. In S. Chaiken \& Y. Trope (Eds.), Dual process theories in social psychology (pp. 423-440). New York: Guilford.

Einhorn, H. J., \& Hogarth, R. M. (1986). Judging probable cause. Psychological Bulletin, 99, 3-19.

Elig, T. W., \& Frieze, I. H. (1979). Measuring causal attributions for success and failure. Journal of Personality \& Social Psychology, 18, 105-115.

Gilbert, D. T., Pelham, B. W., \& Krull, D. S. (1988). On cognitive busyness: When person perceivers meet persons perceived. Journal of Personality \& Social Psychology, 54, 733-740.

Grice, H. P. (1975). Logic and conversation. In P. Cole \& J. L. Morgan (Eds.), Syntax and semantics (Vol. 3, pp. 41-58). New York: Academic Press.

Hansen, R. D., \& Hall, C. A. (1985). Discounting and augmenting facilitative and inhibitory forces: The winner takes almost all. Journal of Personality \& Social Psychology, 49, 1482-1493. 
Hilton, D. (1995). The social content of reasoning: Conversational inference and rational judgment. Psychological Bulletin, 118, 248-271.

Johnson, E. J., HäUbL, G., \& KeInAN, A. (2007). Aspects of endowment: A query theory of value construction. Journal of Experimental Psychology: Learning, Memory, \& Cognition, 33, 461-474.

Kahneman, D., \& FredericK, S. (2002). Representativeness revisited: Attribute substitution in intuitive judgment. In T. Gilovich, D. Griffin, \& D. Kahneman (Eds.), Heuristics and biases: The psychology of intuitive judgement (pp. 49-81). New York: Cambridge University Press.

Kun, A., Murray, J., \& Sredl, K. (1980). Misuses of the multiple sufficient causal scheme as a model of naive attributions: A case of mistaken identity. Developmental Psychology, 16, 13-22.

Lalljee, M., Watson, M., \& White, P. (1982). Explanations, attributions and the social context of unexpected behavior. European Journal of Social Psychology, 12, 17-29.

LEVY, B. J., \& ANDERSON, M. C. (2002). Inhibitory processes and the control of memory retrieval. Trends in Cognitive Sciences, 6, 299-305.

MCCLuRE, J. (1998). Discounting of causes of behavior: Are two reasons better than one? Journal of Personality \& Social Psychology, 74, 7-20.

Miller, E. K., \& Cohen, J. D. (2001). An integrative theory of prefrontal cortex function. Annual Review of Neuroscience, 24, 167-202.

Miller, F. D., Smith, E. R., \& Uleman, J. (1981). Measurement and interpretation of situational and dispositional attributions. Journal of Experimental Social Psychology, 17, 80-95.

Morris, M. W., \& LARRICK, R. P. (1995). When one cause casts doubt on another: A normative analysis of discounting in causal attribution. Psychological Review, 102, 331-355.

Nickerson, R. S. (1984). Retrieval inhibition from part-set cuing: A persisting enigma in memory research. Memory \& Cognition, 12, 531-552.

NisBeTt, R. E., \& Ross, L. (1980). Human inference: Strategies and shortcomings of social judgment. Englewood Cliffs, NJ: Prentice Hall.

OPPENHEIMER, D. M. (2004). Spontaneous discounting of availability in frequency judgment tasks. Psychological Science, 15, 100-105.

OpPENHEIMER, D. M. (2006). Consequences of erudite vernacular utilized irrespective of necessity: Problems with using long words needlessly. Applied Cognitive Psychology, 20, 139-156.

OPPENHEIMER, D. M., \& FranK, M. F. (2007). A rose in any other font would not smell as sweet: Effects of perceptual fluency on categorization. Cognition, 106, 1178-1194.

Oppenheimer, D. M., Tenenbaum, J. B., \& Krynski, T. (2009). Categorization as causal explanation: Discounting and augmenting in a Bayesian framework. Manuscript submitted for publication.

READ, S. J. (1987). Constructing causal scenarios: A knowledge structure approach to causal reasoning. Journal of Personality \& Social Psychology, 52, 288-302.

READ, S. J., \& MARCUS-NEWHALL, A. (1993). Explanatory coherence in social explanations: A parallel distributed processing account. Journal of Personality \& Social Psychology, 65, 429-447.
Rosenfield, D., \& STEPHAN, W. G. (1977). When discounting fails: An unexpected finding. Memory \& Cognition, 5, 97-102.

Schwarz, N. (2004). Meta-cognitive experiences in consumer judgment and decision making. Journal of Consumer Psychology, 14, 332-348.

Tenenbaum, J. B., Griffiths, T. L., \& Kemp, C. (2006). Theory-based Bayesian models of inductive learning and reasoning. Trends in Cognitive Sciences, 10, 309-318.

Thibaut, J. W., \& Riecken, H. W. (1955). Some determinants and consequences of the perception of social causality. Journal of Personality, 24, 113-133.

Tversky, A., \& Kahneman, D. (1973). Availability: A heuristic for judging frequency and probability. Cognitive Psychology, 5, 207-232.

United States Census Bureau (2002). Genealogy name search. Available at www.census.gov/genealogy/www/namesearch.html.

Wimer, S., \& Kelley, H. H. (1982). An investigation of the dimensions of causal attribution. Journal of Personality \& Social Psychology, 43, 1142-1162.

\section{NOTES}

1. Availability is widely believed to be a special case of the more general metacognitive experience of fluency - the feeling of ease associated with mental processes (Schwarz, 2004). Availability specifically refers to ease associated with memory retrieval, but similar fluency effects have been shown in perceptual, conceptual, spatial, linguistic, and embodied domains (for a review, see Alter \& Oppenheimer, 2009).

2. This statistic is correcting for a lack of independence of observations, since each participant responded to all 17 pairs. This is why the $n$ is not a whole number. If one does not correct for violations of independence, $\chi^{2}(1, n=1,601)=465.19, p<.01$.

3. One might wonder why the Water versus Vero pair trended in the other direction. One possible explanation is that the name Waters is, due to morphology, easily confusable with the surname Water. It turns out that Waters is the 429th most common name in the U.S. population and is considerably more frequent than either Vero or Water. This may account for the discrepant finding.

4. Ironically, Levy and Anderson (2002) argued against an indirect suppression account of this phenomenon. However, indirect suppression accounts are prevalent in the literature (e.g., E. K. Miller \& Cohen, 2001), and, as such, this counterexplanation for spontaneous discounting needs to be accounted for.

5. The trend did not hold for the name Bush. It is highly likely that this is due to a floor effect. Very few participants believed Bush to be more frequent, regardless of condition.

(Manuscript received September 21, 2008; revision accepted for publication February 18, 2009.) 